
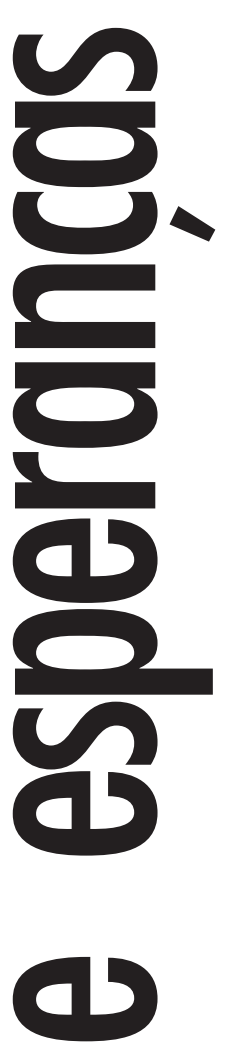

\section{LÊNIA MÁRCIA} MONGELLI é professora do Departamento de Letras Clássicas e Vernáculas da USP.

\section{Ano Mil. Tempo de Medo} ou de Esperanca?, de

Hilário Franco Júnior, São Paulo, Companhia das Letras, 1999.
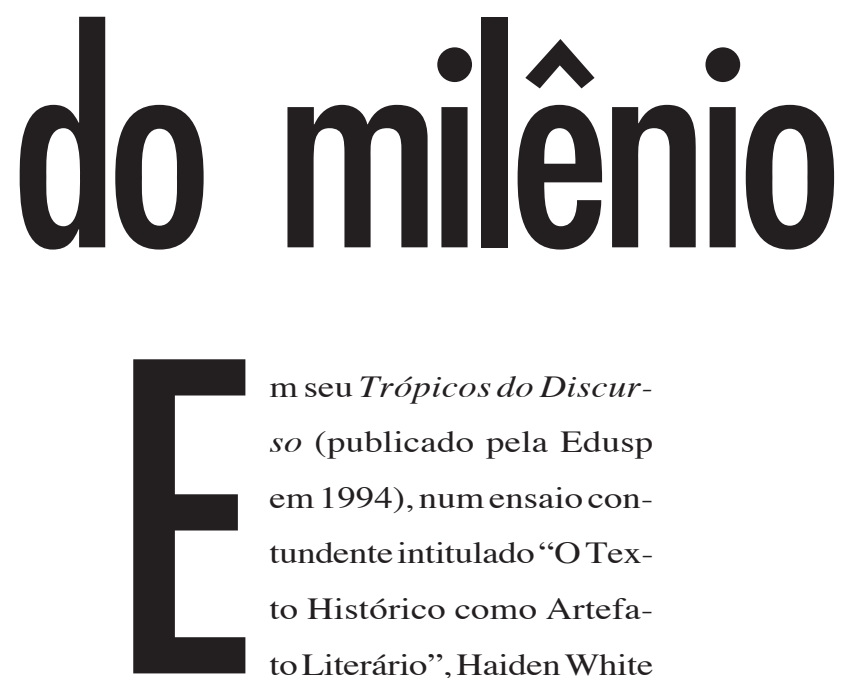

m seu Trópicos do Discurso (publicado pela Edusp em 1994), num ensaio contundente intitulado "OTexto Histórico como Artefato Literário", Haiden White apontava, já em 1974, a zona limítrofe entre História e Literatura, significando aquela parcela de ficção que todo documento histórico contém, até o aparentemente mais objetivo de tipo cartorial, à espera de um certo "olhar" do historiador, que desvendará as entrelinhas e arranjará o conjunto segundo determinada interpretação. Esta parcela de subjetividade no cerne do crivo analítico e de qualquer metodologia adotada para o exame do texto, devidamente matizada pelos indispensáveis procedimentos científicos, situa-se na confluência da crítica literária, cujo objeto de trabalho apenas inverte a ordem de interesses e concentra-se na linguagem metafórica, em que se dissolvem os demais elementos. Atentos a esse espaço de intersecção, o historiador e o literato perseguem fins semelhantes, mesmo que por caminhos diversos. O intuito de ambos é dar um sentido à realidade, de que resulta uma forma tão variável e peculiar quantos são os enfoques adotados. Por isso temos tantas "histórias" da Revolução Francesa, do Romantismo, da Guerra de Canudos, da Semana de 22, etc. 
O raciocínio parece óbvio; mas, entre nós, pouquíssimos o colocam em prática dos dois lados da fronteira, História ou Literatura. Hilário Franco Júnior, medievalista de formação refinada, presidente da Associação Brasileira de Estudos Medievais (Abrem), ocupa posição de destaque no âmbito dessa historiografia percucientemente exercida. Não bastassem seus últimos livros para comprová-lo, dois deles premiados publicamente por instituições de incentivo à pesquisa ( A Eva Barbada, Edusp e Cocanha - História de um País Imaginário, Companhia das Letras), há muito Hilário vem defendendo posição teórica paralela à de White, na linha do que tem chamado de "cultura intermediária" - em moda na Europa e claramente filiada à escola de Jacques Le Goff, já com sólidas raízes plantadas por continuadores no solo da ciência histórica moderna. Se não se pode negar o império da cultura erudita-clerical durante toda a Idade Média, e nem a permanência de resíduos pagãos, de feição oralizante, através da cultura popular, a sutileza está em reconhecer as atitudes mentais que em diversas circunstâncias e diferentes momentos aproximam, entrelaçam, transfundem os dois segmentos, o erudito e o popular - num intercâmbio ("intermediário") de valores que condena a priori qualquer radicalismo partidário. Hilário aplica rigorosamente o método à extensa documentação que estuda, buscando nela o que os clérigos ocultaram e os leigos não puderam dizer, reagindo por equivalências a estímulos freqüentemente opostos. O resultado é uma forma (nos termos de White) de conceber o mundo medieval, exposta com o zelo e a paixão do scholar.

O leitor tem novamente a chance de conferir a excelência do modelo, agora aplicado a motivo mais atual do que nosso famigerado "500 anos": o próximo milênio, a virada do século, verdadeiro ímã temático para a sociedade globalizada com vistas no 2000 , perdida nas ofertas tentadoras das agências de turismo. Por entre o rol de absurdos que têm sido publicados sobre a data em suas ligações com o passado, e com a memória em trabalhos importantes sobre o primeiro milênio (Duby, Focillon, Delumeau, N. Cohn), somos brindados com a incursão de Hilário pelo Ano Mil - caminho que ele escolheu para, na verdade, refletir criticamente sobre o segundo milênio, parecidíssimo com o primeiro por trás de todas as diferenças. Num manual de exíguas 86 páginas, mais 25 de ricas notas e bibliografia, realiza-se a laboriosa aplicação de um método e emerge uma forma interpretativa, que se serve da tradição exegética para também iluminá-la, acrescentando-se doravante como título indispensável aos interessados no assunto.

O parecer elogioso pode justificar-se a partir do subtítulo da obra: "tempo de medo ou de esperança?”. A pergunta envolve séculos de doutrinação, de distorções, de avanços e recuos das esferas do poder, de mobilidade dos estratos populares, a fazer com que as duas opções de resposta (medo $e$ esperança) sejam possíveis, dependendo do ângulo de visão de quem examina a questão. Para destrinchar o nó e o entrecruzamento de posições, conceitos como o de “escatologia”, “apocalipsismo”, “milenarismo", "fim do mundo" vão sendo circunscritos às suas dimensões mais reais, pelo simples fato de se inseri-los, como deve ser, no contexto amplo dos fenômenos histórico-culturais. Com isso, O Ano Mil de 
Hilário extrapola de seu pequeno e enganador formato, para erguer-se como agudíssima consciência do homem moderno, que deve mirar-se nos seus ancestrais do primeiro milênio não por saudosismo passadista, e muito menos por falso orgulho de superação, mas para avaliar melhor seus vizinhos na longa duração histórica.

Metodologicamente, o livrinho foi cerebrinamente concebido e tem estrutura circular, começando e terminando pela proposta de que a passagem para 2000 equivale à transição para 1000 da perspectiva do imaginário universal. O ponto centrífugo é a noção de tempo, angustiante ontem e hoje, anulador de barreiras. Portanto, estamos no terreno de categorias que por si sós negam a ainda resistente impressão de muitos brasileiros sobre a atualidade da Idade Média e a procedência da inclusão de estudos medievos nos currículos nacionais: como se pergunta Hilário a cada passo de sua conclusão, por que, no recesso das emoções humanas, a epidemia da Aids seria mais temível do que foi a da peste negra? Em que as atrocidades cometidas pelas invasões bárbaras ficam a dever às ameaças de extermínio da guerra nuclear? Quantos de nossos políticos têm sido identificados ao Anticristo? Por que todo mundo continua perscrutando avidamente os céus à passagem de um cometa?

O mesmo raciocínio quase matemático dispõe os capítulos: na introdução, corroborando o que dissemos atrás, discorre-se sobre "o tempo, esse desconhecido"; o belo capítulo I, "um ano polêmico", atende à inegável vocação teórica de Hilário, com situar delimitadamente o objeto da investigação (o ano mil, na faixa de 980 a 1040 , como Duby, de modo a englobaro milenário da Encarnação e o milenário da Paixão 1033) e sua opção metodológica, cuja eficácia os demais capítulos testarão; em II, III e IV, aquilo que o ano mil representou de indeterminação, iminência e desejo do "fim do mundo", respectivamente tratado quer pela "cultura clerical", quer pela “cultura vulgar" ou pela "cultura intermediária”; na conclusão, a summa entrevista na rica metáfora do "tempo de Jano", o deus pagão da "transição" (de seu nome deriva o do primeiro mês do ano), cuja dupla face está como que voltada para o passado e para o futuro, ícone das ambigüidades do fluxo temporal. Completam o panorama numerosas ilustrações feitas de imagens iconográficas, minuciosamente comentadas em sintonia com o texto. Parece que nada escapou às lentes de Hilário, em seu intuito de pensar com serenidade e sólida erudição o Ano Mil, sem descartar nenhuma vertente - o que é deveras admirável em tão reduzido número de páginas.

Os grandes medievalistas da atualidade têm tratado sistematicamente a questão do tempo. Trabalhando com uma cultura de predominância cristã como é a da Idade Média Ocidental, o retorno às origens do cristianismo nutre-se da síntese irradiadora de Santo Agostinho, que, tanto nas Confissões quanto em A Cidade de Deus, refletiu, cheio de perplexidade, sobre os mistérios da Igreja assentados na essência da tempo-

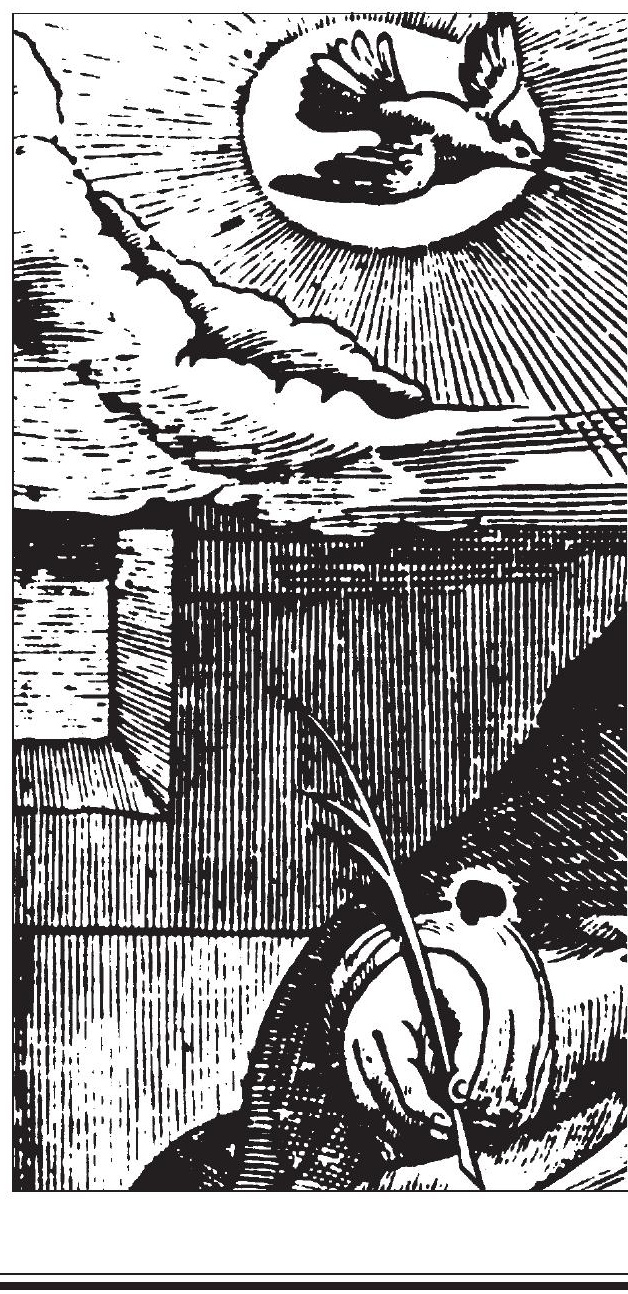


ralidade - lição retomada e ampliada por seus sucessores, até se transformar num dos pilares orientadores da Reforma Gregoriana. Tenha-se uma idéia dos meandros e dos desvãos obscuros que o tema envolve: a concepção de tempo do cristianismo "começa com a Criação ('no princípio Deus criou o céu e a terra'), passa pela Encarnação ('quando chegou a plenitude dos tempos, Deus enviou seu Filho nascido de uma mulher') e termina no Juízo ('o tempo está próximo'). Tempo, portanto, linear e irreversível, mas que surgido em contexto pagão e agrário não podia escapar a certa circularidade, presente em pelo menos dois aspectos da vida medieval. Um, a liturgia que rememorava periodicamente os principais episódios da história sagrada cristã e definia as festas que ritmavam o ano. Outro, o ciclo das estações que determinava o momento das atividades produtivas e familiares naquela sociedade totalmente dependente da natureza. Ou seja, o tempo medieval, mais do que linear, era espiralado, caminhava para seu fim absoluto porém não de forma direta, e sim por meio de oscilações repetitivas". Subentende-se, nessa cronologia, a fonte das mudanças: “o Deus que se tornara homem", o nascimento de Cristo, determinando a criação do "sistema da Era Cristã" e a elaboração de um novo calendário (pp. 8-9). A instabilidade dessas circunvoluções, obrigando à constante reeducação de hábitos e costumes, tem como certa apenas a idéia daquele "fim absoluto" que muitos fazem coincidir com o término do milênio. Em sua sibilina exegese do Juízo Final, a que dedica todo o Livro Vigésimo de A Cidade de Deus, Santo Agostinho detém-se no espinhoso dogma da justiça divina a separar bons e maus na derradeira hora, para concluir, pleno de dúvidas, acerca dos ínvios caminhos do Pai: "Quando chegarmos ao Juízo de Deus, tempo propriamente chamado dia do Juízo e, às vezes, dia do Senhor, reconheceremos a jus-

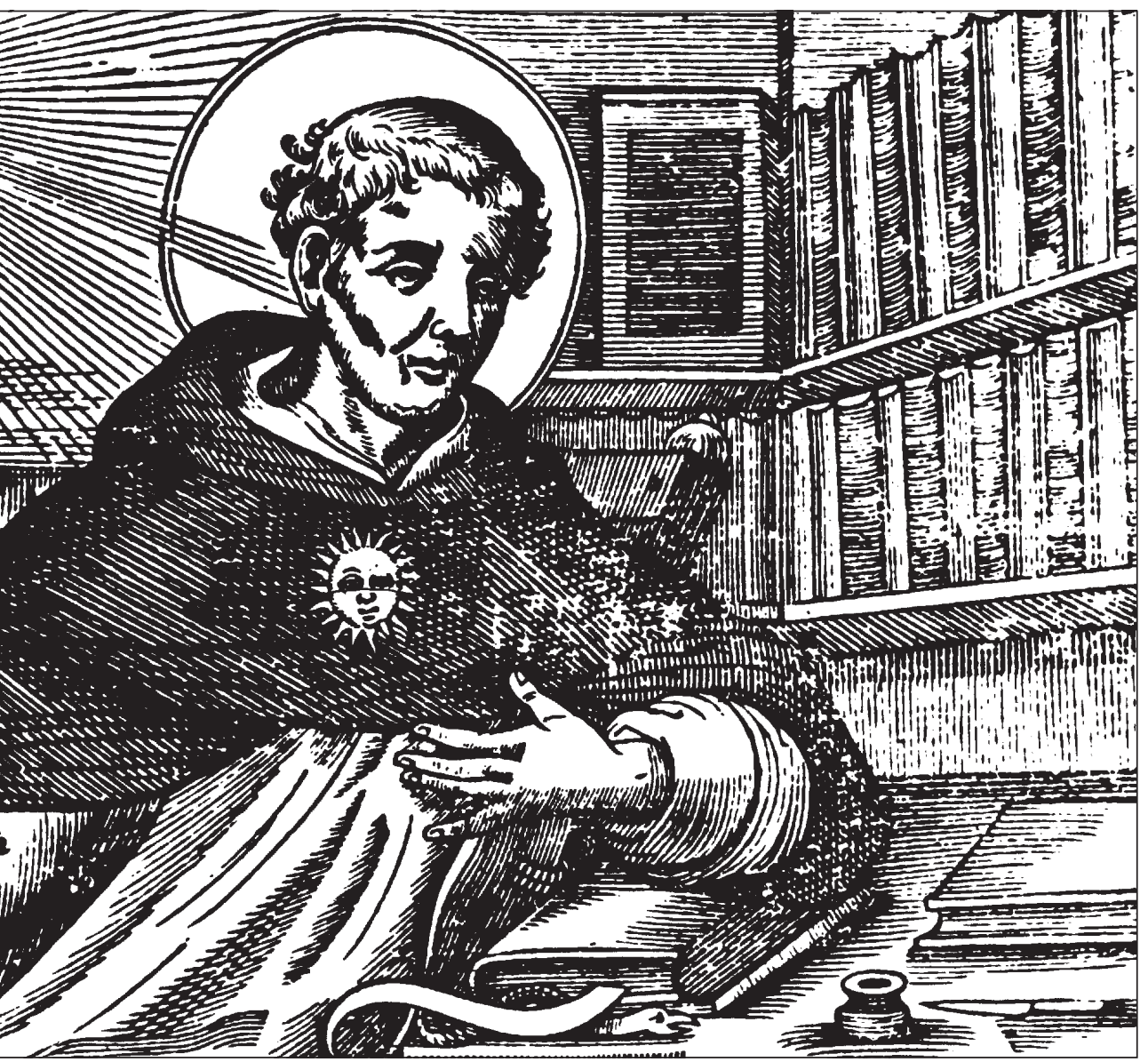

Retrato

de Santo

Agostinho por

Vittore

Carpaccio 
tiça dos Juízos de Deus, não apenas dos emitidos nesse último dia, mas também dos emitidos desde o princípio e dos que emitirá até o referido momento. Aí também aparecerá por que justo juízo Deus faz com que todos os seus justos juízos se ocultem de nossos sentidos e de nossa razão" (Vozes, vol. II, p. 427). Ou seja, a vida do cristão é medida por um andamento de tempo em que ele não pode interferir, só aceitar como inexorável. Quaisquer variações giram em torno desse centro desestabilizador.

Mas Hilário insiste em que evitemos "extremismos interpretativos" que supervalorizem o papel da Igreja, ou pelo menos de uma certa Igreja - aquela identificada com a cultura clerical, herdeira do racionalismo da filosofia antiga, cuja ortodoxia não tem como fechar as portas à penetração da cultura vulgar. Se as diretrizes do pensamento erudito são antes de tudo escatológicas, o homem comum, o leigo e o iletrado estavam às voltas com realidades bem mais próximas e imediatas, decorrentes do conturbado período que se seguiu ao esfacelamento do Império Carolíngio e das novas hordas de invasões, além da crise que a própria Igreja atravessava (acentuada entre 888 e 1057), abrindo a guarda para o paganismo e as heresias. As transformações em curso desembocaram na chamada "revolução feudal", que no fundo era uma tentativa de reordenação da Europa fragmentada, premida pela expansão demográfica propulsora de "crises" diversas e da afirmação de novas camadas populacionais, a reagir com freqüência às imposições do poder estabelecido, Igreja ou Estado. A força que adquirem os mitos messiânicos, a figura do Anticristo, as manifestações do Diabo, etc., são claro indício de reações paralelas e "marginais", mecanismos de contestação de uma Ordem que não mais satisfaz, que parece insuficiente para explicar o mundo.

Portanto, a complexidade do contexto histórico-cultural em que devem ser inseridas as interpretações do primeiro milênio (e/ou do segundo) alerta contra os perigosos dualismos radicalizantes. Para contorná-los, Hilário busca resposta - magnífica e penetrante resposta! - na imagem mediadora dos quatro cavaleiros do Apocalipse, encarnação da guerra, fome, epidemia e morte, flagelos que antecederão o fim do mundo. Segundo o crítico, aí está uma significativa linha de intersecção: para fazer frente às terríficas ameaças de destruição, todos - clérigos e leigos - se unem em movimentos coletivos como os que propuseram a Paze a Trégua de Deus (as Cruzadas, as peregrinações), no recrudescimento do culto aos santos e aos mortos para aplacar a ira divina, na valorização das relíquias como "amuletos" protetores, na realização de procissões principalmente contra "calamidades meteorológicas”, etc. De uma maneira ou de outra, as profecias do Apocalipse bíblico e de seus apócrifos pairam sobre o Ocidente, desencadeando reações que se expressam por muitas bocas em diferentes espaços e em diversos momentos - plurivalência a considerar, se quisermos ser isentos: "Vi então um anjo que descia do céu, tendo na mão a chave do abismo e uma grande corrente. Prendeu o dragão, a antiga serpente, que é o Diabo e Satanás, e o acorrentou por mil anos. Jogou-o no abismo, que fechou e lacrou com um selo, para não seduzir mais as nações até que se completem mil anos, depois do que será solto por pouco tempo" (Apocalipse, 20, 1-4).

Encerro voltando ao ponto de partida. Como o leitor terá percebido, O Ano Mil de Hilário Franco Júnior realiza uma forma de “olhar" o milênio medieval em suas inegáveis conexões com nossa "modernidade". Se o brilho do ensaio se mantém no mesmo elevado patamar de A Eva Barbada e da Cocanha, é porque o historiador tem plena consciência de que a erudição se organiza em linguagem e que a conciliação é tanto mais difícil quanto mais amplo o saber. Por isso o estilo do autor vem sendo depurado a cada publicação - em busca da precisão, da economia, da clareza, da clássica “justa medida", atento, com a humildade necessária, às correções que lhe são sugeridas. Presidindo à seriedade acadêmica há uma postura ética que faria as delícias do intelectual da Antigüidade e ajuda a crer que nem tudo está perdido para o segundo milênio. 